\title{
THE INSTITUTE OF BIOLOGY
}

T HE tenth anniversary of the foundation of the Institute of Biology was celebrated by a dinner held in the restaurant of the Zoological Society of London on January 8, 1960.

It may be recalled that the first general meeting of the Institute was held at King's College, London, on January 5, 1950, when more than 150 biologists were present, representing most branches of the subject. This meeting, however, was only a culmination of more than three years activity (see Nature, 168,131 ; 1951). A council of fourteen members was elected, with Dr. E. Hindle as president, Prof. J. F. Danielli as honorary secretary, and Dr. R. J. C. Harris as honorary treasurer. Rules of membership were drawn up, and an office was established in the British Medical Association House, Tavistock Square, with a general secretary and staff. The membership reached about 500 by the end of the year and has steadily increased so that by the end of 1959 it numbered 2,250 , with 260 overseas members.

Each year the Institute has held a symposium on some subject of general biological interest and published the papers and discussions. The first symposium in 1950 was on "Biological Hazards of Atomic Energy", and the topic for 1960 was "Biology of Space Travel". Freezing and drying, biology of deserts, biology of the sea, numbers of man and animals, biological aspects of the transmission of disease, the biology of ageing, the biological productivity of Britain, the effects of pollution on living material, and problems arising from the control of pests and diseases indicate the wide range of topics which have been discussed at successive meetings; and the records of these symposia are of considerable value to students in these respective fields.

The Institute's widening activities necessitated larger premises, and in 1955 a move was made to the present quarters at 41 Queen's Gate, London, S.W.7. At the same time, nine local branches have been founded: six in Britain, one in Northern Ireland, another in Eire, and one in Malaya. These local branches hold meetings independently of the central organization.

The Institute represents the views of biologists on various national and local bodies concerned with technical education, and played an active part in promoting the scheme for endorsed certificates, which is now firmly established with courses in some dozen centres. The Ministry of Education has now joined the Institute in endorsing certificates; and the Scottish Education Department, with the co-operation of the Institute of Biology, has instituter a National Certificate in Biology.

The Institute publishes a quarterly journal containing news of general interest to biologists, as well as articles on broad topics and book reviews. One of its publications, "Biology as a Career", is now in its third edition; in addition, advice on this subject is given to student members, parents, youth advisory officers and teachers. Also two surveys on salaries were undertaken, during 1953 and 1956.

The Institute maintains an appointments register for the use of members seeking advice on potential employers and vacancies, a service of especial value to overseas members. It also publishes a list of fulltime consultants on biological subjects, including a list of topics for which the services of occasional consultants can be obtained. The Institute also maintains an information service for the use of members, Government departments, firms and the general public, and is consulted on a wide range of biological subjects.

On various occasions the Council of the Institute has made representations of their views to various Ministers of State on matters affecting the development of biological research. Through the medium of the Parliamentary and Scientific Committee, assistance is given to keep members of Parliament informed of the biological background to such problems as food supplies, ageing, Colonial research, pollution, etc.

The officers of the Institute have been selected with the object of obtaining as wide a representation as possible of the various branches of the subject. The office of president, restricted to two years duration. has been held successively by Dr. E. Hindle, Prof. F. E. Fritsch, Sir James Gray, Prof. W. H. Pearsall and Dr. A. S. Parkes. The honorary secretaries have been Prof. J. F. Danielli, Dr. G. E. Fogg and Mr. H. J. Bunker ; and honorary treasurers, Dr. R. J. C. Harris, Dr. N. E. Hickin and Mr. W. V. Harris. The general secretary, Mr. D. J. B. Copp, has served the Institute since 1951, having previously been assistantsecretary of the British Association.

\section{NUCLEAR SCIENCE IN THE MIDDLE EAST}

T $\mathbf{T}$ might be thought a bold experiment to hold $a_{0}$ nuclear science conference in an area which is only just beginning to make progress in this field; never. theless, the symposium held in Hamadan during July 6-18 was an undoubted success.

The symposium was organized by the CENTO (Central Treaty Organization) Institute of Nuclear Science in Tehran (see Nature, 186, $513 ; 1960$ ), and all ten of its scientific staff took part. The total number of participants was about sixty, as follows :

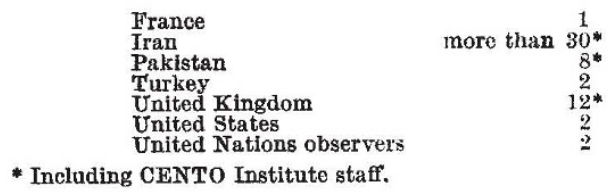

The French and United Nations participants were experts on various missions in Iran. Delegates' expenses were met from CENTO funds, from the 